\title{
Implementação de um sistema computacional, com técnicas de realidade virtual, para auxiliar na educação ambiental
}

\author{
Macedo, C. N., Universidade Tecnológica Federal do Paraná, cakinho_cm@hotmail.com, \\ Santos, José Airton Azevedo, Universidade Tecnológica Federal do Paraná, airton@utfpr.edu.br, \\ Ostrovski, Crizieli Silveira Universidade Tecnológica Federal do Paraná, crizieli@utfpr.edu.br.
}

\section{RESUMO}

A universidade está a buscar constantes avanços e inovações, conduzindo a um processo inovador de troca de informações rápidas e/ou instantâneas. Assim, lida-se em todos os momentos do cotidiano com a informação e a tecnologia. No ambiente escolar isto também se processa, conseqüentemente, a escola não pode ignorar todo o conhecimento acessível e disponível através da informática, que nos disponibiliza softwares educativos, internet, entre outros recursos. $\mathrm{O}$ artigo propõe o uso de técnicas de realidade virtual para fornecer conhecimentos básicos sobre os componentes de um sistema de geração fotovoltaica, de energia elétrica, em uma residência. No ambiente virtual, construído neste trabalho, através da linguagem de programação VRML, o usuário pode "navegar" pelos cômodos de uma casa virtual, identificando os componentes do sistema fotovoltaico e suas respectivas cargas.

Palavras-Chave: realidade virtual, sistema fotovoltaico, recurso pedagógico, educação.

\section{Computational implementation of a system, with techniques for virtual reality, for auxiliary in environmental education}

\begin{abstract}
The university is to seek constant improvements and innovations, leading to an innovative process of rapid exchange of information and/or instant. So, read up on all the everyday moments with the information and technology. In the school environment that also takes place, consequently, the school can not ignore all the knowledge available and accessible through the computer, which provides in educational software, internet, among other features. The paper proposes the use of virtual reality techniques to provide basic knowledge about the components of a system for photovoltaic generation of electricity in a residence. In the virtual environment, built on this work through the programming language VRML, the user can "navigate" through the rooms of a virtual home, identifying the components of the photovoltaic system and their loads.
\end{abstract}

Key-Words: virtual reality, photovoltaic, teaching resource, education.

\section{INTRODUÇÃO}

A sociedade está vivenciando um período de transformações, com uma economia sofrendo interferência global, supervalorizando a comunicação e a informação, tornando-se cada vez mais dependente da tecnologia (Tajra, 2001).

Toda esta informação está presente no cotidiano, tornando-se fundamental sua utilização, e isto não pode ser ignorado pela educação que forma os futuros cidadãos (Lollini, 2000).

O ambiente da informática educativa é ativo; os alunos conversam entre si e entre os 
grupos. Os alunos que melhor conhecem a informática assumem posturas de monitores, e a antiga "ordem" é posta ao lado. O que conta é o aprendizado coletivo e em equipe. As habilidades são desenvolvidas de forma mais natural e sem imposições. Os alunos tornam-se mais expansivos e não tem receios de errar, são hábeis em relação às ferramentas disponíveis (Tajra, 2001).

Neste contexto, o educando passa a construir seu conhecimento através da interação com o meio e com o professor.

A utilização da energia solar na geração de energia elétrica vem progressivamente se apresentando como uma alternativa economicamente viável, sobretudo no meio rural ou em regiões isoladas, onde os custos para instalação de sistemas convencionais são relativamente altos (Treble, 1991). Sistemas fotovoltaicos se caracterizam por sua elevada confiabilidade e pouca manutenção, assim seu elevado custo inicial é compensado pelo baixo custo de operação e manutenção. Suas aplicações se estendem desde sistemas sem acumuladores (baterias), como em calculadoras solares, até sistemas residenciais em locais remotos, estações repetidoras (antenas de celular) e até satélites (CEPEL/CRESEB, 1999).

Atualmente, a Realidade Virtual deixou de ser objeto de estudo de grandes centros de pesquisa e passa a ser conhecida e utilizada por usuários comuns. Tais recursos vêm sendo intensamente abordados e utilizados, despertando assim interesses em profissionais e usuários de diversas áreas (Almeida, 2007).

A linguagem VRML (Modelagem em Realidade Virtual) é uma linguagem, independente de plataforma, que permite a criação de Ambientes Virtuais por onde se pode "navegar", visualizar objetos por ângulos diferentes e até interagir com eles. Existem dois tipos de realidade virtual, a imersiva (sensação de estar dentro de um ambiente) e a não-imersiva. Na realidade virtual imersiva são utilizados acessórios (luvas, sensores, capacete de visualização) de modo que o usuário seja completamente envolvido com o Ambiente Virtual. Já a realidade virtual não imersiva, caracteriza-se pela utilização de equipamentos interativos mais comuns e menos sofisticados. Monitores de vídeo são utilizados para a visualização do ambiente virtual. Dispositivos tradicionais de entrada, como o mouse e o teclado, servem para que o usuário possa interagir com o ambiente virtual criado (Bissochi, 2003).

A realidade virtual fornece experiências de primeira - pessoa (conhecimento direto e pessoal) que especificamente são projetados para ajudar o usuário a apreender sobre um conteúdo específico. Este tipo de experiência aproveita a interação com o mundo real. Isto torna a realidade virtual especificamente interessante do ponto de vista educacional.

O objetivo deste trabalho foi à construção de uma casa virtual (realidade virtual não imersiva), utilizando a linguagem de programação VRML, para providenciar aos usuários/alunos, conceitos básicos sobre os componentes de um sistema fotovoltaico instalado em uma residência.

\section{MATERIAL E MÉTODOS}

A linguagem VRML é um padrão de formato de arquivo para realidade virtual, utilizado tanto para a internet como para ambientes desktops. Por meio desta linguagem, escrita em modo texto, é possível criar objetos (malhas poligonais) tridimensionais onde podem-se definir cor, transparência, brilho e textura. Os objetos podem ter formas básicas, como: esferas, cubos, ovóides, hexaedros, cones e cilindros. Ou formas criadas pelo próprio programador, como as extrusões. Não é necessário um software específico para a criação de arquivos VRML (embora 
existam), uma vez que os objetos podem ser todos criados em modo texto.

A linguagem VRML usa o sistema cartesiano 3D. A seqüência dos eixos é $\mathrm{X}, \mathrm{Y}$ e $\mathrm{Z}$ e a unidade de medida para distâncias são metros e para ângulos, radianos. A medida para distância não é definida formalmente, mas adotou-se, neste trabalho, o metro como unidade de medida.

\section{Nodes}

É um conjunto de especificações que determinam as características dos objetos contidos no cenário (Cardoso, 2007). Os nodes definem a hierarquia e as características individuais de cada objeto dentro do contexto geral. O node descreve o tipo do objeto, que pode ser uma esfera, um cilindro, uma transformação, uma definição de luz ou textura, etc. Também define as características de cada um, como tamanho de um cubo, diâmetro de uma esfera, intensidade da luz ambiente, cor, etc.

Sintaxe para definição de um node:

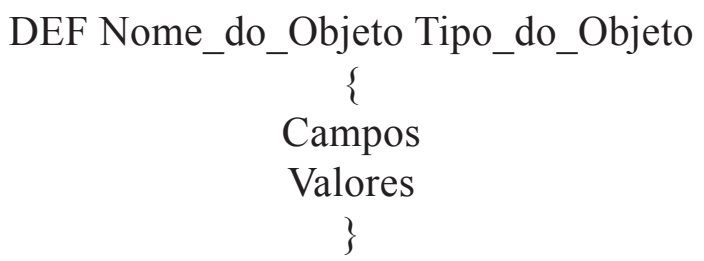

A arquitetura do sistema, proposto neste trabalho, utilizou os recursos oferecidos pela linguagen VRML. O sistema foi constituído pelos seguintes módulos:

\section{Módulo dos Objetos Virtuais}

Este módulo contém um conjunto de objetos que abrange os dispositivos elétricos, módulos solares e seus equipamentos, os objetos de decoração da casa - móveis dos diversos cômodos e a estrutura da casa.

\section{Módulo da Interface Gráfica}

Este módulo oferece ao usuário o cenário do ambiente virtual, permitindo a visualização e a "navegação" no mundo virtual.

\section{RESULTADOS E DISCUSSÃO}

O fornecimento de energia elétrica para casa virtual é realizado através de um painel fotovoltaico (Figura 1).

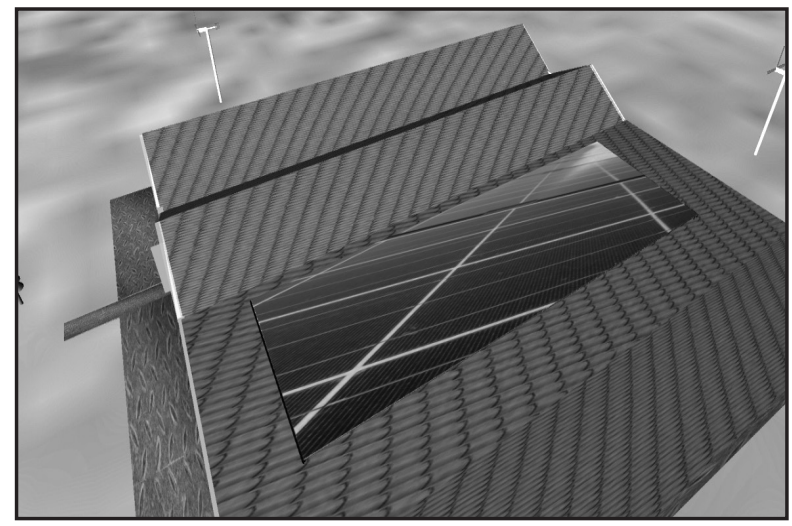

Figura 1: Painel fotovoltaico.

O usuário pode "navegar" pelos cômodos da casa virtual, onde pode visualizar: os componentes do sistema fotovoltaico (painel fotovoltaico, bancos de baterias (Figura 2 ), etc) e as cargas do gerador de energia alternativa (iluminação (Figura 3), geladeira (Figura 4), televisão, etc).

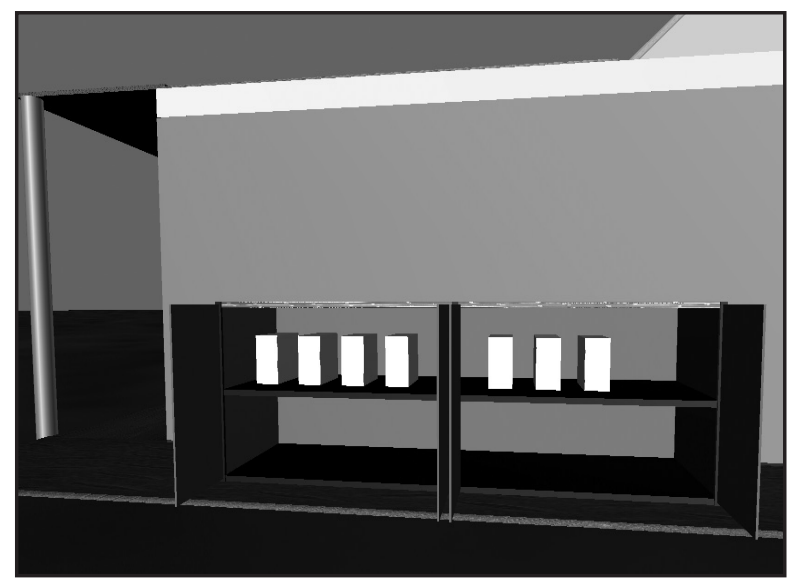

Figura 2: Banco de baterias. 


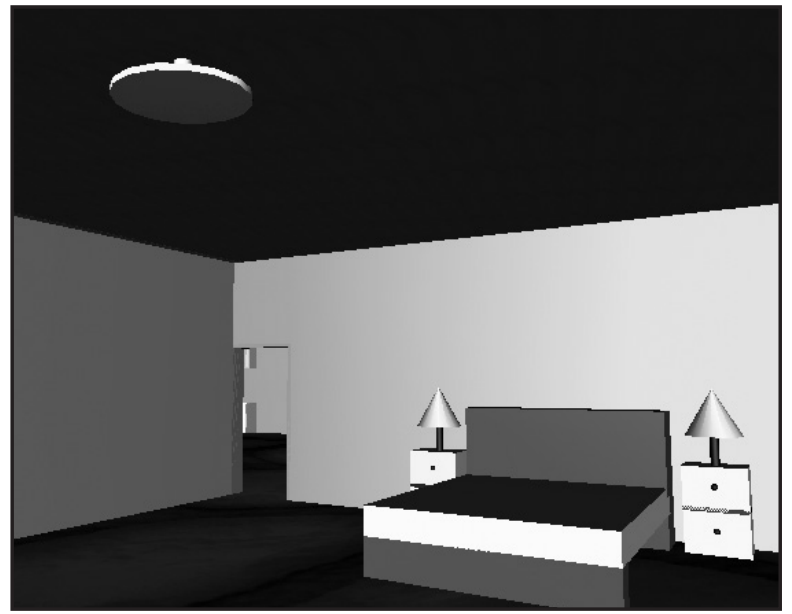

Figura 3: Carga - iluminação.

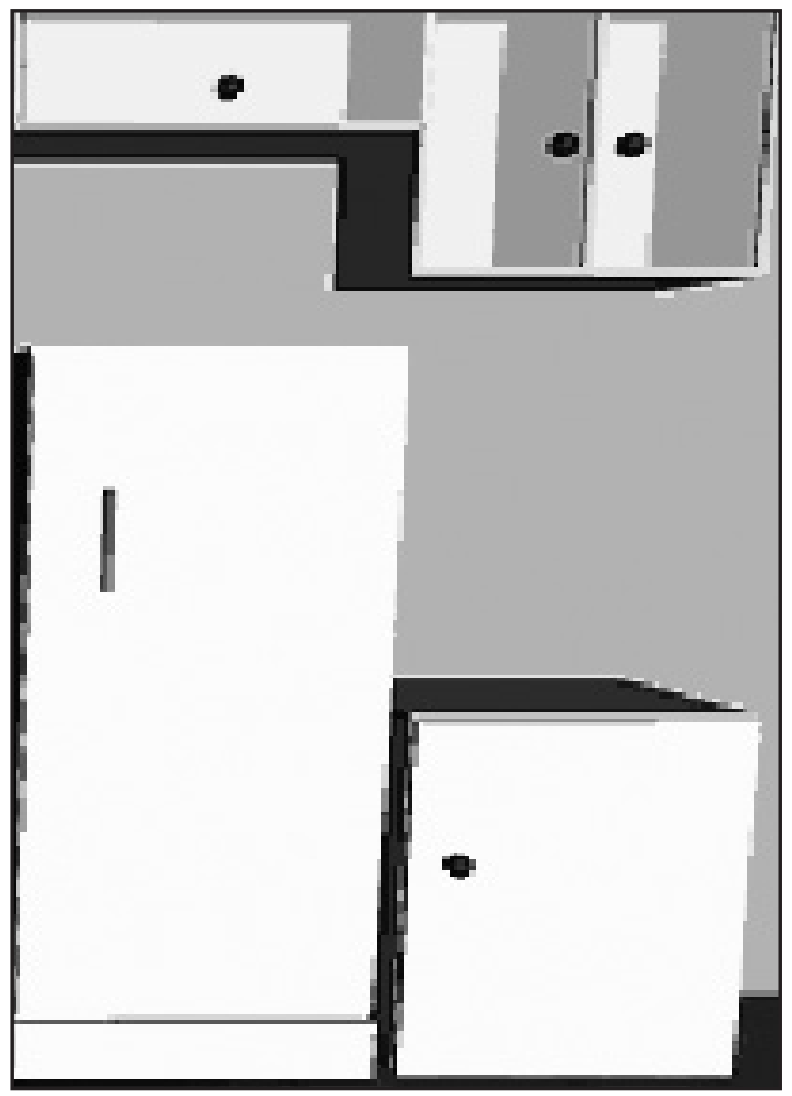

Figura 4: Carga - geladeira.

Num dos cômodos, da casa virtual, foi colocado um painel com a descrição dos componentes do sistema alternativo de geração de energia elétrica e suas respectivas cargas (Figura 5).

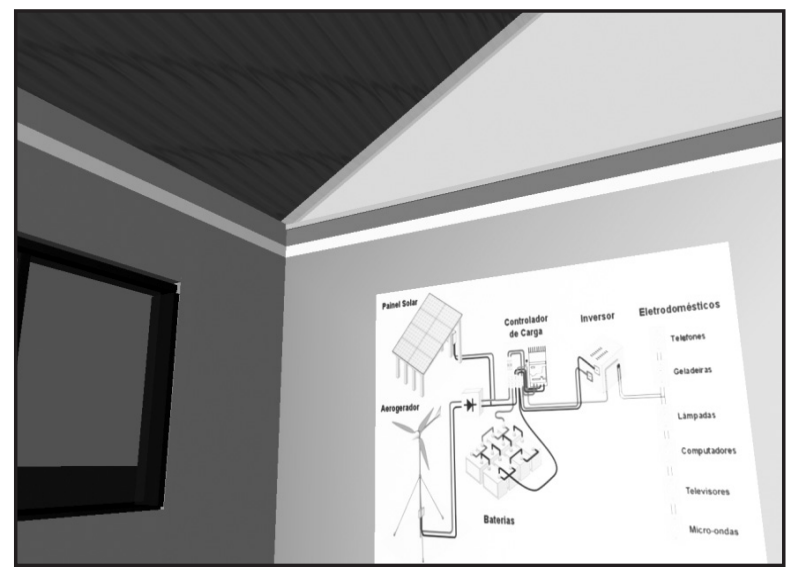

Figura 5: Componentes do sistema.

Os equipamentos que constituem o sistema são: painel fotovoltaico, banco de baterias, controlador de carga, inversor de freqüência e as cargas. A descrição básica de cada um deles é fornecida, ao usuário, através de outros painéis (Figura 6).

Banco de Baterias
Em sistemas isolados, necessita-se que a
energia elétrica esteja disponivel durante as 24
horas do dia (principalmente a noite para
iluminação), e durante 365 dias no ano,
mesmos naqueles dias críticos, com muita
nebulosidade. A função da bateria é armazenar
energia gerada deixando-a sempre disponível,
estabilizar a tensão do sistema e servir como
reserva de potência quando necessário.
As baterias mais utilizadas em sistemas
fotovoltaicos são as estacionárias de chumbo
ácido seladas que são usualmente mais caras
que as automotivas mas duram um tempo
maior (podem operar com ciclos diários de
carga e descarga mais profundos), o que pode
ser importante para locais isolados e com
pouca estrutura para troca das mesmas.

Figura 6: Banco de baterias. 
No contato com a escola constata-se que a informática está presente no cotidiano de grande parte da comunidade escolar. Neste contexto, à ferramenta computacional, desenvolvida neste trabalho, pode ser utilizada como recurso pedagógico para o ensino de fontes alternativas de energia (energia solar). Assim, à escola com a utilização dos recursos tecnológicos, possibilitaria ao aluno uma junção entre o ambiente e a tecnologia, contribuindo para a busca de melhor utilização do meio ambiente.

\section{CONCLUSÕES}

A crise energética nos remete imediatamente para a questão ambiental, visto que o assunto energia é inerente em todos os seus ramos e conceitualizações ao meio ambiente, afetando assim, o individuo na parte econômica, social, tecnológica, entre outras.

Como existe um limite para as reservas de combustíveis fosseis, o consumo de energia, verificado durante muitos anos, não pode continuar indefinidamente. A energia solar é uma fonte de energia muito atraente, porque a quantidade de energia disponível, para o consumo, é várias vezes o atual consumo energético mundial.

Apesar de não estarem isentas de provocarem algumas alterações no meio ambiente as fontes renováveis de energia são, hoje, as melhores opções para um futuro sustentável para a humanidade.

A casa virtual, implementada neste trabalho, foi uma iniciativa que visou gerar conhecimentos dirigidos à área de fontes alternativas de geração de energia elétrica, no caso a energia solar. Utilizando como meio, ou ferramenta, a tecnologia da realidade virtual. Através de projetos dessa natureza pode-se sensibilizar o usuário/aluno, com relação à utilização de fontes de energia renovável, a partir de sua interação e investigação.

\section{REFERÊNCIAS BIBLIOGRÁFICAS}

ALMEIDA, M. Desvendando os 3ds Max. São Paulo: Digerati Books, 2007.

BISSOCHI, F. ET all Utilizando técnicas de realidade virtual para o estudo da conservação de energia solar em elétrica. São Pedro; CLAGTEC 2003, 2003.

CARDOSO, A. Tecnologias para o desenvolvimento de sistemas de realidade virtual e aumentada. Recife: UFPE, 2007.

CEPEL/CRESESB Manual de engenharia para sistemas fotovoltaicos. Rio de Janeiro: CEPEL/CRESESB, 1999.

FERREIRA, L.; BONETI, L. Educação e sociedade. Rio Grande do Sul: UNIJUI, 1999.

GUIMARÃES, M. A dimensão ambiental na educação. Campinas: Papirus, 2001.

LOLLINI, P. Didática \& computador: quando e como a informática na escola. São Paulo: Loyola, 2000.

OLIVEIRA, R. Informática educativa: dos planos e discursos a sala aula. Campinas: Papirus, 2000.

TAJRA, S. F. Informática na educação: novas ferramentas pedagógicas para o professor da atualidade. São Paulo: Érica, 2001 .

TREBLE, F. C. (1991) Generanting electricity from the sun. New York: Pergamon Press, 1991. 